\title{
Assessing vitamin D safety following fortification and supplementation intake scenarios using the EFSA Comprehensive Database: the ODIN approach
}

\author{
S. Pigat ${ }^{1}$ and M. Kiely ${ }^{2}$ \\ ${ }^{1}$ Creme Global Ltd., 4th Floor, The Tower, Trinity Technology \& Enterprise Campus, Grand Canal Quay, Dublin 2, \\ Republic of Ireland and \\ ${ }^{2}$ Cork Centre for Vitamin D and Nutrition Research, School of Food and Nutritional Sciences, University College Cork
}

Recent data from the EC-funded ODIN project on vitamin D [Food-based solutions for Optimal vitamin D Nutrition and health through the life cycle; EC Contract 613977] show that the prevalence of vitamin D deficiency in Europe, using a threshold for serum 25 -hydroxyvitamin $\mathrm{D}(25(\mathrm{OH}) \mathrm{D})$ of $30 \mathrm{nmol} / \mathrm{L}$, is 1 in $8^{(1)}$. Thus, it is clear that strategies for vitamin $\mathrm{D}$ deficiency prevention are required ${ }^{(2)}$. As the natural dietary supply is insufficient to meet vitamin $\mathrm{D}$ requirements, careful application of fortification (nutrient addition in controlled amounts) and bio-fortification (enrichment of animal food sources, e.g. meats, eggs, fish, mushrooms) approaches could safely increase vitamin D intakes across the population distribution and prevent deficiency ${ }^{(3)}$. This study aimed to assess the safety of a range of fortification and supplementation scenarios into the European food supply.

The EFSA Comprehensive Database ${ }^{(4)}$ was used to provide an indication of average vitamin D exposure and safety of various intervention strategies. The EFSA Comprehensive Database aims to harmonise data from 20 member states and 32 food surveys, via the FoodEx classification system. Its main use is as a screening tool to assess chemical exposure. Data vary in their availability, quality, methodology, granularity and year of assessment. Specific vitamin D-containing food groups were matched to the level 2 FoodEx system. As intake at individual food level is not available, a conservative approach for specific food groups and their vitamin D content was taken by applying the highest vitamin D concentration possible within a given food group. Dietary supplements were assumed to be $100 \%$ vitamin D supplements. Mean and P95 vitamin D exposure were assessed for each food group and consecutively for the total diet. For the P95, the eight highest intakes were summed to estimate total dietary intakes. The table shows data from Italy and Sweden as examples.

\begin{tabular}{|c|c|c|c|c|}
\hline \multirow[b]{2}{*}{ Vitamin D Intake Scenarios } & \multicolumn{2}{|c|}{ Italy $^{(5)}(\mu \mathrm{g} /$ day $)$} & \multicolumn{2}{|c|}{ Sweden $^{(6)}(\mu \mathrm{g} /$ day $)$} \\
\hline & $\overline{\text { Mean }}$ & P95 & Mean & P95 \\
\hline Baseline & $12 \cdot 1$ & $16 \cdot 9$ & $9 \cdot 8$ & $17 \cdot 9$ \\
\hline $\begin{array}{l}\text { Fortification + Bio-Fortification } \\
\text { Milk: } 2 \mu \mathrm{g} / 100 \mathrm{~g} \\
\text { Beef: } 1 \mu \mathrm{g} / 100 \mathrm{~g} \\
\text { Pork: } 1.7 \mu \mathrm{g} / 100 \mathrm{~g} \\
\text { Eggs: } 6.74 \mu \mathrm{g} / 100 \mathrm{~g}\end{array}$ & $27 \cdot 4$ & $39 \cdot 2$ & $35 \cdot 3$ & 55.0 \\
\hline $\begin{array}{l}\text { Fortification + Bio-Fortification + Supplements } \\
\text { Supplements: } 50 \mu \mathrm{g} / \mathrm{day}\end{array}$ & 38.9 & $89 \cdot 2$ & $36 \cdot 6$ & 103.9 \\
\hline
\end{tabular}

A worst-case scenario approach placed vitamin D intakes from fortification and bio fortification well below the Upper Level of Intake (UL) of $100 \mu \mathrm{g} /$ day. Conservative addition of supplementation at $50 \mu \mathrm{g} /$ day exceeded the UL at the P95.

This project received funding from the European Union's Seventh Framework Programme for research, technological development and demonstration under grant agreement no. 613977.

1. Cashman KD, Dowling KG, Skrabakova Z, et al. (2016) Am J Clin Nutr 103(4), 1033-1044.

2. Kiely M, Cashman KD. (2015) Nutr Bull 40; 235-246.

3. Black LJ, Walton J, Flynn A, Cashman KD, Kiely M. (2015) J Nutr 145(5):969-76.

4. European Food Safety Authority (2011) EFSA J 9(3).

5. Leclercq C, Arcella D, Piccinelli R, et al. (2009) Publ Health Nutr 12(12), 2504-2532.

6. Becker W and Pearson M (2002) National Food Administration, 1-201. 